\title{
Pattern of occurrence and treatment of impacted teeth at the Muhimbili National Hospital, Dar es Salaam, Tanzania
}

Farizana Msagati, Elison NM Simon ${ }^{*}$ and Sira Owibingire

\begin{abstract}
Background: Impacted teeth predispose to periodontal disease and dental caries of adjacent teeth resulting in pain, discomfort and loss of function. This study analyzed the pattern of occurrence of impacted teeth, associated symptoms, treatment and complications of treatment in patients who presented at the Muhimbili National Hospital, Tanzania.

Method: This was a crossectional descriptive study which utilized notes and $\mathrm{x}$ rays of patients who were treated for impacted teeth at the Oral and Maxillofacial firm in Muhimbili National Hospital over five years, from January 2005 to August 2010. These records were retrieved and examined for the major complaint of the patient at presentation to hospital, demography, impacted tooth, type of impaction (for third molars), treatment offered and complications after treatment. Similar information was collected from all patients with impacted teeth attended in the same centre from $1^{\text {st }}$ September 2010 to $31^{\text {st }}$ August 2011.
\end{abstract}

Results: A total of 896 patients ( 496 males and 400 females) treated for complaints related to impacted teeth were recorded. The male to female ratio was 1.2:1, age range of 16 to 85 years and a mean age of 28.9 years (SD $=9.5)$. Slightly more than $84 \%$ of the patients presented with mandibular third molar impactions. Most (44.7\%) of these patients had an impacted lower right third molar followed by those presenting with a lower left third molar impaction (39.7\%). In $1.3 \%$ of the patients all the four third molars were impacted. Sixty nine (7.7\%) patients had impacted upper $3^{\text {rd }}$ molars while $2 \%$ had impacted upper canines. Of the mandibular $3^{\text {rd }}$ molar impactions 738 (76\%) were mesio-angular type, 87 (8.9\%) horizontal type and 69 (7.1\%) disto-angular.

Patients presented with a variety of complaints. About $85 \%$ of the patients presented to hospital due to varying degrees of pain. In $4.9 \%$ the detection of the impacted tooth/teeth was coincidental after presenting to hospital for other reasons not related to the impaction.

Majority of the patients with impacted mandibular third molars had carious lesions on the impacted teeth, neighbouring tooth or both. Four hundred and five (45.2\%) patients had a carious lesion on one of the impacted teeth while 201(22.4\%) patients had a carious lesion on the adjacent second molar. In 122 (13.6\%) patients both the impacted third molar and the adjacent second molar were carious. In twelve patients who presented with a main complaint of fracture of the angle of the mandible there was an associated impacted $3^{\text {rd }}$ molar. Eight hundred and fifteen (91\%) patients with impacted teeth were treated by surgical removal. Among these only $15(1.8 \%)$ had complications that ranged from excessive swellings, trismus and severe pain post operatively. One patient was reported to have fracture of the angle of the mandible sustained during surgical removal of an impacted 48. (Continued on next page)

\footnotetext{
*Correspondence: esmjema@yahoo.com

Oral and Maxillofacial Unit, Muhimbili National Hospital, Dar es Salaam,

Tanzania
}

\section{Biomed Central}

(c) 2013 Msagati et al.; licensee BioMed Central Ltd. This is an Open Access article distributed under the terms of the Creative Commons Attribution License (http://creativecommons.org/licenses/by/2.0), which permits unrestricted use, distribution, and reproduction in any medium, provided the original work is properly cited. 
(Continued from previous page)

Conclusions: The majority of patients with impacted teeth were young with an almost equal sex distribution. The most commonly impacted teeth were mandibular third molars followed by the maxillary third molars. Patients with impacted teeth reported for health care predominantly because of pain due to dental caries or infection.

There is a need of creating appropriate programmes that would further raise peoples' awareness to regular dental checkups so that appropriate measures are taken before complications arise.

Keywords: Impacted teeth, Pattern of occurrence, Muhimbili, Tanzania

\section{Background}

Impacted teeth fail to erupt fully into the oral cavity within the expected time due to impact with the jaw bone, adjacent tooth or even the gums [1-3]. Lack of an adequate dental arch length and space in which to erupt into is the main reason for this failure. Studies have shown the mandibular last molar to be the most commonly impacted tooth followed by the maxillary third molars, the maxillary canines and the mandibular premolars [3-7]. Impaction of the incisors is relatively rare compared to the other teeth and when present the cause is often a retained decidous tooth or the presence of another abnormality like an odontoma [8-10]. Multiple impactions are in most instances seen in association with some syndromes such as cleidocranial dysostosis, Gardner's syndrome, Gorlin-Sedano syndrome and YunisVaron syndrome [11-15]. A case of impactions of primary teeth which is generally rare was reported, however, this was associated with tooth agenesis in a monozygous twin [16]. Impacted teeth are usually painless but when infections of surrounding tissues occur, severe pain result. Pressure on the inferior alveolar nerve in very deeply positioned lower third molar impactions may be another reason for pain $[1,17]$. Presence of impacted teeth predisposes the erupted adjacent teeth to periodontal disease and caries formation [18,19]. In Turkey, Mollaoglu (2002) in a study of volunteers found out that the mesiodistal angulation of the third molars was significantly greater while the retromolar space of the third molar was significantly smaller in the impacted group [20]. Chu et al. (2003) in a study of a Hong Kong Chinese population showed that eight percent of teeth adjacent to impacted mandibular third molars had periodontal loss of more than $5 \mathrm{~mm}$ and caries was found in the same surfaces in $7 \%$ of the adjacent second molars [4]. Symptoms associated with impacted mandibular third molars were reported in 30\% of patients in Nigeria [17]. Oginini (2002) reported infections in patients with impactions ranging from pulpitis, pericoronitis and periodontitis [21]. Some studies reported that $96.1 \%$ of impacted mandibular third molars were removed under local anaesthesia while $2.9 \%$ were done under general anaesthesia and were often accompanied by some complications $[17,22]$. The only retrievable study done in Tanzania was epidemiological [23].
The aim of this study therefore was to analyze the pattern of occurrence of impacted teeth, associated symptoms, treatment and complications of treatment in patients presenting at the oral and maxillofacial unit of the Muhimbili National Hospital.

\section{Methods}

This was a crossectional descriptive study which utilized notes and $\mathrm{x}$ rays of patients who were treated for impacted teeth at the Oral and Maxillofacial firm in Muhimbili National Hospital over five years, from January 2005 to August 2010. These records were retrieved and examined for the major complaint of the patient at presentation to hospital, demography, impacted tooth, type of impaction (for third molars), treatment offered and complications after treatment. Similar information was collected from all patients with impacted teeth attended in the same centre from $1^{\text {st }}$ September 2010 to $31^{\text {st }}$ August 2011.

Information collected was recorded in a special form. A tooth was considered to be impacted if it failed to erupt fully into the oral cavity. However, specifically for the $3^{\text {rd }}$ molars, $x$ rays were further used to analyze the type of impaction while reference was made to the adjacent second molar [23-27]. Two lines, each drawn separately along the longitudinal axes of the adjacent second molar and the impacted $3^{\text {rd }}$ molar were used to determine whether the impaction was vertical, mesioangular, distoangular or horizontal [25,27]. Also, the relationship of the upper part of the crown of the impacted tooth to the occlusal surface of the adjacent fully erupted second molar was used to determine the levels of the impacted teeth. In patients who the second molar for any reason happened to be missing this classification was not used. The $\mathrm{x}$ rays were interpreted by a single person (ES- second author) who has vast experience in oral radiology. Intra examiner variability was done by randomly repeating $10 \%$ of the radiographs to ascertain consistency throughout the study with a reproducibility of $89 \%$.

Treatment in all of the cases was carried out after a thorough analysis of the type of impaction, condition of the crown e.g. whether it was grossly carious, amount of overlying bone, proximity with the adjacent tooth and presence of infection. Horizontally impacted teeth 
Table 1 Distribution of the patients by age and sex

\begin{tabular}{cccc}
\hline Age group (yrs) & Male & Female & Total \\
\hline $15-19$ & 6 & 13 & 19 \\
$20-24$ & 102 & 104 & 206 \\
$25-29$ & 149 & 162 & 311 \\
$30-34$ & 113 & 76 & 189 \\
$35-39$ & 72 & 12 & 84 \\
$40-44$ & 32 & 16 & 48 \\
$45-49$ & 16 & 12 & 28 \\
$50-54$ & 2 & 1 & 3 \\
$55-59$ & 4 & 0 & 4 \\
$\geq 60$ & 0 & 4 & 4 \\
Total & $\mathbf{4 9 6}(\mathbf{5 5 . 4 \% )}$ & $\mathbf{4 0 0}(\mathbf{4 4 . 6 \% )}$ & $\mathbf{8 9 6}$ \\
\hline
\end{tabular}

required substantial bone removal and sectioning of the tooth. Except for patients with established infection, no medications were prescribed to patients prior to the anticipated surgery. However, post extraction analgesics and broad spectrum antibiotics were prescribed to all patients. Complications that arose during and after treatment were recorded.

Data was entered into computer and analyzed using SPSS programme (version 15). Frequency distribution was generated to describe the demographic characteristics of the study population, the different impacted teeth and types of mandibular $3^{\text {rd }}$ molar impactions and complications after treatment.

\section{Ethical issues}

Ethical clearance for the study was issued by the research and publications committee of the Muhimbili University of Health and Allied Sciences through the Department of Preventive and Community Dentistry School of Dentistry. Patients were informed on the purpose of the research, assured of strict confidentiality and requested for their consent. Their consent to participate or not would not affect their management.

\section{Table 2 Patient's different main presenting complaints}

\begin{tabular}{llrr}
\hline Ser. No. & Presenting complaints & N & \% \\
\hline 1. & Mild pain & 23 & 2.9 \\
2. & Moderate pain & 69 & 8.7 \\
3. & Severe pain & 587 & 73.8 \\
4. & Pain and paraesthesia & 15 & 1.9 \\
5. & Pain and swelling & 46 & 5.8 \\
6. & Aesthetics & 8 & 1.0 \\
7. & Other & 47 & 5.9 \\
& Total & $\mathbf{8 9 6}$ & $\mathbf{1 0 0 . 0}$ \\
\hline
\end{tabular}

Table 3 Complications that resulted from treatment of impacted teeth

\begin{tabular}{lll}
\hline Ser No. & Complication & $\mathbf{N}$ \\
\hline 1. & Severe pain & 6 \\
2. & Post operative swelling & 4 \\
3. & Trismus & 2 \\
4. & Swelling and trismus & 2 \\
5. & Fracture during the operation & 1 \\
Total & & $\mathbf{1 5}$ \\
\hline
\end{tabular}

\section{Results}

A total of 896 patients (496 males and 400 females) who reported to hospital and were found to have impacted teeth were recorded and included in the study (Table 1). The male to female ratio was 1.2:1, age range of 16 to 85 years and a mean age of 28.9 years $(\mathrm{SD}=9.5)$.

Slightly more than $84 \%$ of the patients presented with mandibular third molar impactions. Most (44.7\%) of these patients had an impacted lower right third molar followed by those presenting with a lower left third molar impaction (39.7\%). In $1.3 \%$ of the patients all the four third molars were impacted. About $7.7 \%$ of the patients had an impacted upper $3^{\text {rd }}$ molar while $2 \%$ had an impacted upper canine. Of the mandibular $3^{\text {rd }}$ molar impactions $738(76 \%)$ were mesio-angular type, 87 (8.9\%) horizontal type and 69 (7.1\%) disto-angular.

Patients presented with a variety of complaints (Table 2). About 85 per cent of the patients presented to hospital due to varying degrees of pain. In $4.9 \%$ the detection of the impacted tooth/teeth was coincidental after presenting to hospital for other reasons not related to the impaction.

Majority of the patients with impacted mandibular third molars had carious lesions on the impacted teeth,

Table 4 Distribution of patients according to the different types of impacted teeth

\begin{tabular}{llcc}
\hline Ser. No. & Impacted tooth/teeth & \multicolumn{2}{c}{ Frequency } \\
\cline { 3 - 4 } & & $\mathbf{n}$ & $\%$ \\
\hline 1. & Lower right third molar & 402 & 44.7 \\
2. & Lower left third molar & 356 & 39.7 \\
3. & Both lower left and lower right third molars & 62 & 6.9 \\
4. & Upper right third molar & 21 & 2.4 \\
5. & Upper left third molar & 16 & 1.7 \\
6. & Both upper right and upper left canines & 11 & 1.2 \\
7. & All four 3 $3^{\text {rd }}$ molars & 13 & 1.4 \\
8. & Upper right canine & 7 & 0.8 \\
9. & Upper left canine & 7 & 0.8 \\
10. & Lower right first premolar & 2 & 0.2 \\
11. & Both lower right and left first premolars & 2 & 0.2 \\
Total & & $\mathbf{8 9 9}$ & $\mathbf{1 0 0}$ \\
\hline
\end{tabular}




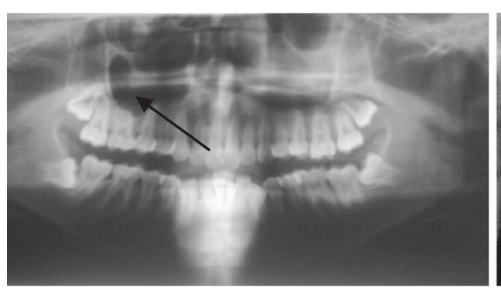

A

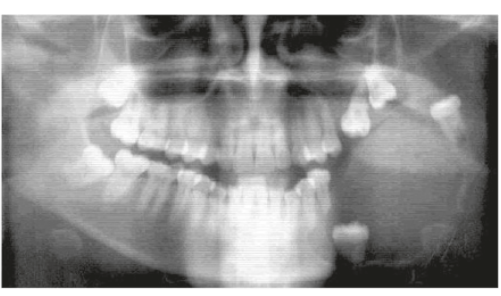

B

Figure 1 Incidental findings in patients presenting with impacted teeth. A. An OPG of a young patient who presented with a painless swelling on right side of the upper jaw (arrow) and was incidentally found to have all last molars impacted. B. A big pathological lesion possibly predisposed by presence of impacted teeth.

neighbouring tooth or both. Four hundred and five (45.2\%) patients had a carious lesion on one of the impacted teeth while $201(22.4 \%)$ patients had a carious lesion on the adjacent second molar. In 122 (13.6\%) patients both the impacted third molar and the adjacent second molar were carious. In twelve patients who presented to hospital because of fracture of the mandible there was an associated impacted $3^{\text {rd }}$ molar. Eight hundred and fifteen (91\%) patients with impacted teeth were treated by surgical removal. Among these only 15 (1.8\%) had complications that ranged from excessive swellings and trismus and severe pain post operatively (Table 3). One among these patients was reported to have suffered fracture of the angle of the mandible sustained during surgical removal of an impacted 48 .

\section{Discussion}

This was a hospital based study whereby information on patients who presented with complaints related to impacted teeth or those presenting for other complaints but coincidentally were found to have impacted teeth was collected. In some situations the impacted teeth, although presenting symptoms, could not be clearly visualized in the oral cavity making radiological examination the only means of reaching a substantive diagnosis and planning of appropriate management.

There were slightly more males than females who reported with impacted teeth, however, the age profile was almost similar for both (Table 1). The mean age of patients with impactions as was found in this study was slightly higher compared to reports from Europe and America $[3,20]$. This might be explained by the fact that in those countries impactions are discovered during routine dental examinations which start at younger ages [28-30]. On the other hand in resource poor countries and for Tanzania in particular, majority of the patients report for health care only after experiencing symptoms that lead to a certain degree of incapacitation which varies from mild to severe pain, swellings, trismus or fever.

In this study, the most (89.3\%) commonly impacted teeth were mandibular $3^{\text {rd }}$ molars (Table 4). These findings are in concurrence with the findings from other studies $[6,17,21,31]$. The reasons for this occurrence have been explained by others [32,33]. There were few patients who were found to have multiple impactions (Figure 1A). Often these were coincidental findings when patients presented with either complaints from only one of them or a completely different complaint unrelated to the impactions (Figure 2). Impacted canines and premolars were a rarity $(<15 \%)$ most possibly because when impacted these teeth often interfere with aesthetics therefore were removed at younger ages. Furthermore, patients with teeth that did not erupt into the oral cavity generally did not present any complaints but rather the findings were incidental. Conversely, impacted molars that partially appeared in the oral cavity were

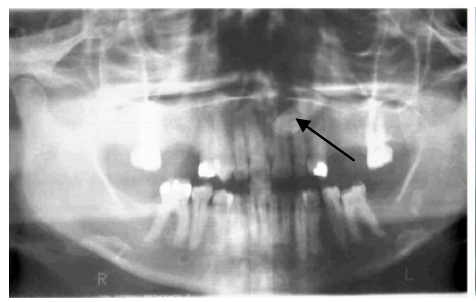

A

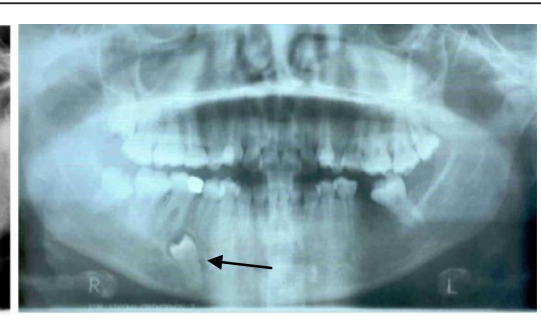

B

Figure 2 Symptomless impacted teeth. A. The buried upper left canine (arrow) was coincidentally found in this patient who presented with TMJ problems. B. Buried supernumerary lower right premolar (arrow) that had no symptoms. The same patient had impacted upper and lower right third molars. 


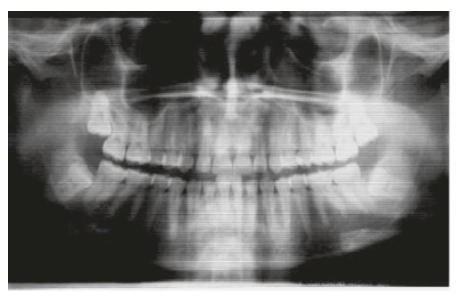

A

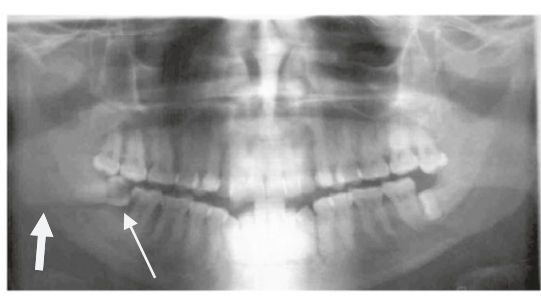

B

Figure 3 Multiple impacted teeth. A. An OPG of a 27 years old lady with all $3^{\text {rd }}$ molars impacted. She had no complaints. B. Bilateral mandibular $3^{\text {rd }}$ molar impactions. Both 47 and 48 are carious (narrow arrow) and the patient sustained fracture in the region of the lower right $3^{\text {rd }}$ molar (thick arrow).

found to be responsible for a number of problems including severe pain from pulpitis due to caries or pericoronitis (Figures $1 \mathrm{~B}$ and $3 \mathrm{~B}$ ).

Most $(76 \%)$ of the third molar impactions were mesioangular, above or at the level of the cervical margin of the adjacent second molar. This poised several disadvantages; once a portion or the whole crown of the impacted tooth was exposed to the oral environment the interplay between food substrates and oral bacteria could easily lead to the development of caries. This is further aggravated by the fact that adequate cleanliness of the whole or part of the surface of the impacted tooth and the distal surface of the neighbouring tooth becomes almost impossible. This most possibly explains why in this study $46.6 \%$ of the patients were found to have caries on the impacted tooth and $36 \%$ had caries on the adjacent tooth (Figure 1).

In this study over $80 \%$ of the patients reported varying degrees of pain and incapacitation, with 73\% experiencing severe pain (Table 2). Only 5\% of the patients did not present any complaints at all. Pain mostly resulted from pulpitis due to deep carious lesions on the impacted tooth, the adjacent one or on both (Figure 3B). Delay in seeking appropriate medical or dental health care was the main reason for the severe pain that patients presented with. Delay in reporting for oral health care in Tanzanian communities has been attributed to ignorance, social-cultural factors and lack of adequate oral health care services in the country [34].

The fact that only 15 (1.8\%) suffered complications after surgical treatment reflects a good success level in the methods of treatment applied in this centre (Table 3). Weakening of the crown due to gross caries, amount of overlying bone, proximity to the adjacent tooth and presence of infection were important factors taken into consideration during treatment planning. The position and depth of the impacted tooth, particularly the mandibular third molar, compromises the strength of this bone predisposing it to fractures at the angle (Figure 3A). In such situations therefore, surgical bone removal through drilling with a bur, tooth resection and elevation were done with great care.

Contrary to the practice elsewhere $[2,35]$, and unless otherwise dictated by an underlying systemic condition, patients were not routinely given medication prior to the anticipated surgery. Swellings a day or two after surgery were accompanied by differing levels of trismus. This is similar to reports from other African and European studies $[3,19,21,36]$. Postoperative pain of different degrees was also one of the complaints of patients postoperatively. Similar to other studies in some cases this was because of either an infected or dry socket [21,36]. The pain was managed by reassurance, the use of common analgesics and obtundents. The patient who was reported to have suffered fracture at the angle of the mandible during treatment had a deeply lying horizontally impacted $3^{\text {rd }}$ molar. This emphasizes the need for an adequate sectioning of the tooth to avoid the necessity of the use of excessive force during removal [37].

\section{Conclusion}

The majority of patients with impacted teeth were rather young with an almost equal sex distribution. The most commonly encountered impacted tooth was mandibular third molar followed by the maxillary third molars. Patients with impacted teeth reported for health care predominantly because of pain due to dental caries or infection and only in very few cases were the patients aware of the existence of the impactions.

Appropriate programmes that will further raise peoples' awareness on the importance of regular dental checkups which could lead to an early detection of impacted teeth and institution of appropriate measures before complications arise are necessary.

Competing interests

The authors declare that they have no competing interests whatsoever.

\section{Authors' contributions}

FM was the principal investigator and took part in the design of the study and data collection, ENMS assisted with the designing of the study, 
treatment of the patients and collection of data and SO treated some of the patients, took part in data collection and preparation of the manuscript. All authors read and approved the final manuscript.

\section{Authors' information}

FM was a researcher working for elective period study, ENMS and SO are specialist oral and maxillofacial surgeons and lecturers in the Department of Oral and Maxillofacial Surgery of the Muhimbili University of Health and Allied Sciences.

\section{Acknowledgements}

We appreciate the assistance extended by the Department of Oral and Maxillofacial unit, particularly the staff in the emergency room where all the patients were attended.

\section{Financial support}

Financial support was extended by the Muhimbili University of Health and Allied Sciences through the Department of Community and Preventive Dentistry.

Received: 24 November 2012 Accepted: 26 July 2013

Published: 6 August 2013

\section{References}

1. Kruger G: Oral maxillofacial surgery. 6th edition. Saunders, London: Mosby Co; 1984.

2. Petterson, Ellis E, Hupp J, Tucker M: Contemporary oral and maxillofacial surgery. 3rd edition. Philadelphia: CV Mosby; 1998.

3. Brakus I, Filipovic Z, Boric R, Siber S, Svegar D, Kuna T: Analysis of impacted and retained teeth operated at the department of Oral Surgery, School of Dental Medicine, Zagreb. Coll Antropol 2010, 34:229-233.

4. Chu FC, Li TK, Lui VK, Newsome PR, Chow RL, Cheung LK: Prevalence of impacted teeth and associated pathologies - a radiographic study of the Hong Kong Chinese population. Hong Kong Med J 2003, 9:158-163.

5. Tarzona BA, Paredes VB, Llamas JM, Cibrian RE, Gandia JL: Influence of first and second premolar extractions or non extraction treatments on mandibular third molar angulation and position. A comparative study. Med Oral Patol Oral Cir Bucal 2010, 15:760-766.

6. Padhye MN, Dabir AV, Girotra CS, Pandhi VH: Pattern of mandibular third molar impactions in the Indian population: a retrospective clinicoradiographic survey. Oral Radiol Oral Surg Oral Med Oral Pathol 2012 (Ahead of Publ).

7. Zuccati GC, Doldo T: Multiple impactions in an adolescent girl. Am J Orthod Dentofacial Orthop 2010, 137:163-172.

8. Chokron A, Reveret S, Salmon B, Vermelin L: Strategies for treating an impacted maxillary central incisor. Int Orthod 2010, 8:152-156.

9. Ozan F, Kara I, Ay S: Impacted mandibular permanent incisors associated with a supernumerary tooth; a case report. Eur J Dent 2009, 4:324-328.

10. Peerlings $\mathrm{RH}$ : Treatment of a horizontally impacted mandibular canine in a girl with a class II division I malocclusion. Am J Orthdont Dentofacial Orthop 2010, 137:154-162.

11. Van der Waal I: Disease of the jaws, Diagnosis and treatment. Munskagaard, Copenhagen; 1991.

12. Hohoff A, Joos U, Meyer U, Ehmer U, Stamm T: The spectrum of Apert Syndrome: phenotype, particularities in orthodontic treatment and characteristics of orthognatic surgery. Head Face Med 2007, 3:10-21.

13. Bayar GR, Ortakolu K, Sencimen M: Multiple impacted teeth: report of three cases. Eur J Dent 2008, 2:73-78.

14. D'alessadro G, Tagariello T, Piana G: Cleidocranial dysplasia: Aetiology and stomatognathic and craniofacial abnormalities. Minerva Stomatol 2010, 59:117-127.

15. Sujatha G, Sivapathasundharam B, Sivakumar G, Nalikumar S, Ramasamy M, Prasad TS: Idiopathic multiple impacted teeth: case report and discussion. J Oral Maxillofac Pathol 2012, 16:125-127.

16. Zengin AZ, Sumer AP, Karaarslan E: Impacted primary tooth and tooth agenesis: a case report of monozygotic twins. Eur J Dent 2008, 2:299-302.

17. Obiechina $A E$, Arotiba JT, Fasola AO: Third molar impaction: Evaluation of the symptoms and pattern of impaction of mandibular third molar teeth in Nigerians. Odontostomatol Trop 2001, 24:22-25.
18. Bataineh $A B, A I Q M$ : The predisposing factors of pericoronitis of mandibular third molars in a Jordanian population. Quintessence Int 2003, 34:227-231.

19. Macluskey M, Slevin M, Curran M, Nesbitt R: Indications for and anticipated difficulty of third molar surgery: a comparison between a dental hospital and a specialist high street practice. Br Dent J 2005, 199:671-675.

20. Mollaoglu N, Centiner S, Gungor K: Patterns of third molar impactions in a group of volunteers in Turkey. Clin Oral Investig 2002, 6:109-113.

21. Oginini FO, Ugboko VI, Assam E, Ogunbodede EO: Postoperative complaints following impacted third molar surgery in Ile-Ife, Nigeria. SADJ 2002, 57:264-268

22. Jameison LM, Thomson KF: Dental general anaesthetic receipt among Australians aged 15 years 1998-2005. BMC Oral Health 2008, 8:10.

23. Hashemipour MA, Tahmasbi-Arashlow M, Fahimi-Hnzaei F: Incidence of impacted mandibular and maxillary third molars: A radiographic study in a Southern Iran Population. Med Oral Patol Oral Cir Bucal 2013, 18:40-45.

24. Gupta A, Bhowate RR, Nigam N, Saxena S: Evaluation of impacted mandibular third molar by panoramic radiography. International Scholarly Network SRN Dentistry 2011, 406714:1-8.

25. Sandhu S, Kaur T: Radiographic evaluation of the status of the third molar in the Asian -Indian students. J Oral Maxillofac Surg 2005, 63:640-645.

26. Marciani RD: Third molar removal: an overview of indications, imaging, evaluation and assessment of risk. Oral Maxillofac Surg Clin North Am 2007, 19:1-13.

27. Hattab FN, Alhaija ESJ: Radiographic evaluation of mandibular third molar eruption. Oral Surgery, Oral Med, Oral Path, Oral Rad and Endod 1999, 88:285-291.

28. Fernandes MJ, Ogden GR, Pitts NB, Ogston SA, Ruta DA: Incidence of symptoms in previously symptom-free impacted lower third molars assessed in general dental practice. Br Dent J 2009, 12:207-218.

29. Ventä I, Turtola L, Murtomaa H, Ylipaavalniemi P: Third molars as an acute problem in Finnish university students. Oral Surg Oral Med Oral Pathol 1993, 76:135-40.

30. Angelillo IF, Nobile CG, Pavia M: Survey of reasons for extraction of permanent teeth in Italy. Community Dent Oral Epidemiol 1996, 24:336-40.

31. Komba D, Moshy J: Surgery of wisdom teeth at Muhimbili National Hospital Dar es Salaam Tanzania. Tanz Medical J 2011, 25:19-21.

32. Capelli J: Mandibular growth and third molar impaction in extraction cases. Angle Orthod 1991, 61:223-229.

33. Behbehani F, Artun J, Thalib L: Prediction of mandibular third-molar impaction in adolescent orthodontic patients. Am J Orthod Dentofacia Orthop 2006, 130:47-55.

34. Ngilisho NA, Mosha HJ, Poulsen S: The role traditional healers in the treatment of toothache in Tanga region, Tanzania. Community Dent Health 1994, 11:240-242.

35. Friedman JW: The prophylactic extraction of third molars: a public health hazard. Am J Public Health 2007, 97:1554-1559.

36. Meetin $\mathrm{M}$, Ener I, Tek M: Impacted teeth and mandibular fracture. Eur $J$ Dent 2007, 1:18-20.

37. Chiapaso M, De Cicco L, Marrone G: Side effects and complications, associated with third molar surgery. Oral Surg, Oral Med and Oral Path 1993, 76:412-420

doi:10.1186/1472-6831-13-37

Cite this article as: Msagati et al:: Pattern of occurrence and treatment of impacted teeth at the Muhimbili National Hospital, Dar es Salaam, Tanzania. BMC Oral Health 2013 13:37. 